\title{
An investigation of molecular mechanism and the role of Te-bridged-atom in the formation of polysubstituted pyridines via Hetero-Diels-Alder reaction of isotellurazole with acetylenic dienophile: a molecular electron density study
}

\author{
ABDELILAH BENALLOU* \\ Team of Chemoinformatics Research and Spectroscopy and Quantum Chemistry, Physical and Chemistry Lab, \\ Faculty of Science, University Chouaib Doukkali, B. P. 20, 2300 El Jadida, Morocco \\ E-mail: abdo_benallou@yahoo.fr
}

MS received 17 January 2018; revised 12 March 2018; accepted 2 April 2018; published online 19 July 2018

\begin{abstract}
An electron localization function (ELF) analysis and a detailed computational study of the heteroDiels-Alder (HDA) reaction between isotellurazole and acetylenic dienophile have been performed. Then, B3LYP/Lanl2dz $+6-31+\mathrm{g}(\mathrm{d})$ basis set level has been used to characterize the molecular mechanism and reactivity. The conceptual and computational DFT show that the most favorable regioisomeric product is the ortho/endo adduct, for which the energetic cost is $39.4 \mathrm{kcal} / \mathrm{mol}$. Furthermore, ELF topological analysis envisages that the electron density of the pseudo-radical centers of the most electrophilic and nucleophilic atoms of the molecules come mainly from the charge transfer which takes place along the reaction pathway. The high asynchronicity of the bond formation means that two-stage one-step is the most appropriate mechanism for this reaction. However, the weak electronic contribution of the heavy chalcogen-bridged Tellurium atom in the C1-Te-N2 sequence has increased the activation barrier of the reaction. Otherwise, it has assisted the easy removal of the atom in the intermediary cycloadduct in the end of the reaction leading to the polysubstituted pyridine. So, despite the fact that Te atom is electronically rich, it plays a marginal role for improving reactivity of this [4+2] cycloaddition process.
\end{abstract}

Keywords. ELF topological analysis; NBO; HDA; IRC; conceptual DFT; TST.

\section{Introduction}

The use of Tellurium (Te) atom in synthetic organic chemistry is rare compared to other atoms such as oxygen- or nitrogen-bridged five- or six-membered heteroaromatics. ${ }^{1-5}$ However, Shimada et al., have successfully used the Te atom in the synthesis of polysubstituted pyridines via Hetero-Diels-Alder reaction of isotellurazole with acetylenic dienophile at room temperature. ${ }^{6}$ It is worthy to note that the pyridine cycloadduct is an important natural product in biological, pharmaceutical and agrochemical products. The Hetero-Diels-Alder (HDA) reactions, including a heteroatom such as $\mathrm{O}$, $\mathrm{N}, \mathrm{S}, \ldots$ etc. have significant importance due to their potential for the construction of six-membered heterocycles. ${ }^{7-11}$ This is facilitated by the presence of electron withdrawing group (EWG) in the dienophile, by lowering the activation energy. ${ }^{12}$ In this decade, calculations of the quantum mechanical observables along the reaction pathway have led to the understanding the bond forming and breaking processes. ${ }^{13,14}$ For this purpose, the electron localization function (ELF) ${ }^{15}$ method and bonding evolution theory (BET) ${ }^{16}$ have emerged to analyze the reaction mechanism. ${ }^{17-22}$ In the course of our studies, we evaluated the role of Te-bridged atom in the HDA reaction and highlight the cycloadduct regiochemistry in the HDA reaction of isotellurazole 1 with acetylenic dienophile 2 . Theoretical study has established the formation of intermediary cycloadducts and the subsequent excision of tellurium from the cycloadducts to form polysubstituted pyridines (Scheme 1). ${ }^{6}$

\footnotetext{
*For correspondence

Electronic supplementary material: The online version of this article (https://doi.org/10.1007/s12039-018-1459-7) contains supplementary material, which is available to authorized users.
} 


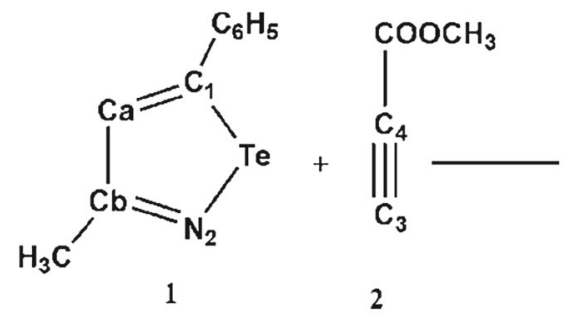

Isotellurazole Acetylenic dienophile
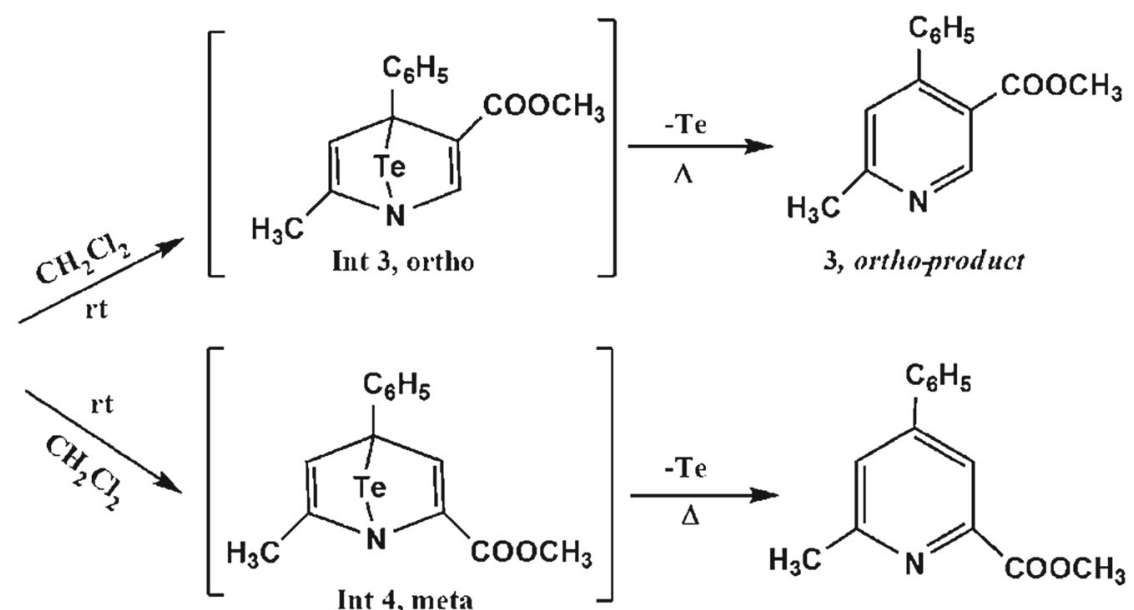

4, metriproduct

Scheme 1. Regioselectivity mode of Hetero-Diels-Alder reaction of isotellurazole with acetylenic dienophile to yield polysubstituted pyridines.

In order to understand the role of Te-bridge in the progress of the HDA reaction and an insight into the nature of transition state and mechanism, the bond formation along the reaction pathway was studied. Effectively, the combination of DFT and ELF theory was used to characterize the reaction pathway through optimized geometries for the corresponding stationary points along the Intrinsic Reaction Coordinate (IRC) path ${ }^{23}$ on the potential energy surface. To this end, the nucleophilic and electrophilic Fukui functions-based frontier molecular orbital (FMO) theory $^{24}$ and Houk rule-based Conceptual DFT (CDFT) were used. Whereas in Houk rule, 'small-small' and 'large-large' type interactions are more favored than interactions 'large-small' and 'small-large'. However, this Houk approach is based essentially on the coefficients of orbital molecular HOMO/LUMO.

\section{Computational}

The optimizations of stationary points were performed using the Berny analytical gradient method, ${ }^{25}$ and the IRC paths ${ }^{26}$ were traced in order to check the energy profiles connecting the transition state (TS) to the two associated minima using the second order Gonzalez-Schlegel integration method. ${ }^{27}$ The electronic structures of stationary points were analyzed by the natural bond orbital (NBO) method ${ }^{28}$ and by ELF topological analysis. ${ }^{12}$ The ELF study was carried out with the Multiwfn program ${ }^{29}$ using the corresponding mono determinant wave functions of the selected structures. All computations were realized using the B3LYP exchange-correlation functional, ${ }^{30}$ together with the standard Lanl2dz basis set level. ${ }^{31}$ This large basis set was successfully used for representing all atomic number mainly for the Te atom, and it has been considered as one of the most reliable basis set with B3LYP hybrid for the heavy atom, however for $\mathrm{N}, \mathrm{O}, \mathrm{C}$ and $\mathrm{H}$ atoms we have employed the $6-31+\mathrm{g}(\mathrm{d})$ basis set. The calculations were performed with the Gaussian 09 suite of programs, ${ }^{32}$ whereas, the charge transfer (CT) was calculated using the natural population analysis (NPA). ${ }^{33}$ The global electrophilicity index $\omega,{ }^{34}$ is given by the following expression, $\omega=\mu^{2} / 2 \eta$, in terms of the electronic chemical potential $\mu$ and the chemical hardness $\eta$. Both quantities was approached in terms of the one-electron energies of the frontier molecular orbital HOMO and LUMO, $\mathrm{e}_{\mathrm{H}}$ and $\mathrm{e}_{\mathrm{L}}$, as $\mu=\left(e_{H}+e_{L}\right) / 2$ and $\eta=\left(e_{L}-e_{H}\right)$, respectively. ${ }^{35}$ Then the local electrophilicity for a site or an atom $(\mathrm{k})^{36}$ is given by the equation: $\omega_{\mathrm{k}}=\omega f_{k}^{+}$. The nucleophilicity index $\mathrm{N},{ }^{37}$ based on the HOMO energies obtained within the Kohn-Sham scheme, ${ }^{38}$ and defined as $\mathrm{N}=\mathrm{E}_{\mathrm{HOMO}(\mathrm{Nu})}-\mathrm{E}_{\mathrm{HOMO}}(\mathrm{TCE})$. Similarly, the local nucleophilicity index $\mathrm{N}_{\mathrm{k}}{ }^{39}$ is defined as the product of global nucleophilic index $\mathrm{N}$ and the nucleophilic of the Fukui index $\mathrm{N}_{\mathrm{k}}=\mathrm{N} f_{k}^{-}$. The nucleophilicity is referred to tetracyanoethylene (TCE), because it presents the lowest HOMO energy in a large series of molecules, where $f_{k}^{-}$and $f_{k}^{+}$are the Fukui functions for nucleophilic and electrophilic attacks, respectively. ${ }^{40}$

\section{Results and Discussion}

In order to establish the nature of the mechanism of the reaction, and to evaluate the changes of electron density along IRC of the HDA reactions between isotellurazole (1) and acetylenic dienophile (2), an analysis of the regioselectivity to choose the most favorable ortho/meta product based on DFT reactivity descriptors was performed; followed by an examination of the stationary points involved in the two regioisomeric patterns associated with the endo approach. Equally, a mechanistic study between isotellurazole $\mathbf{1}$ and acetylenic dienophile 
Table 1. HOMO and LUMO energies, chemical potential $\mu$, chemical hardness $\eta$, global electrophilicity $\omega$ and global nucleophilicity $\mathrm{N}$.

\begin{tabular}{lcc}
\hline Parameter & Isotellurazole & Acetylenic dienophile \\
\hline HOMO $(\mathrm{au})$ & -0.22056 & -0.27545 \\
LUMO $(\mathrm{au})$ & -0.05933 & -0.05921 \\
$\mu(\mathrm{au})$ & -0.140 & -0.167 \\
$\eta(\mathrm{au})$ & 0.161 & 0.216 \\
$\omega(\mathrm{eV})$ & 1.65 & 1.75 \\
$N(\mathrm{eV})$ & 2.87 & 1.11 \\
\hline
\end{tabular}

2 and also a characterization of the $\mathrm{C}-\mathrm{C}$ and $\mathrm{N}-\mathrm{C}$ bondformation step in the HDA reaction has been carried out. Simultaneously, an ELF bonding analysis along the new bond-formation/breaking pathway to this reaction was completed; likewise, an exploration of the role of heavy chalcogen bridged tellurium atom in the advancement of this reaction was achieved.

\subsection{Regioselectivity study and analysis of the local and global descriptors based on CDFT reactivity}

In this part, the characteristics of both isotellurazole (1) and acetylenic dienophile (2) entities are entirely determined, and then the distribution of the global and local electrophilicity and nucleophilicity indices of each molecule was performed; at this point the chemical potential $\mu$ and chemical hardness $\eta$ have been used to characterize and describe the reactivity of these compounds. Thus, the CDFT reactivity indices of diene and dienophile substrates are given in Table 1 .

Here, attention is paid to study the reactivity of the reactants, so we have noted that the chemical potential of isotellurazole is mostly higher compared with the acetylenic dienophile in which $\mu(-0.140)>$ $\mu(-0.167)$, which clearly indicates that the global charge transfer is automatically taking place from diene (isotellurazole 1) to dienophile (acetylenic 2). While, the global electrophilic and nucleophilic index shows that the acetylenic dienophile is more highly electrophilic than that of isotellurazole substrate, where $\omega(1.75)>$ $\omega(1.65)$, so the isotellurazole moiety behaves as nucleophile in this reaction such as $\mathrm{N}(2.84)>\mathrm{N}(1.07)$. Subsequently, on the one hand, the charge transfer will take place from diene (1) to dienophile (2). On the other hand, the polarity of this reaction is moderate.

Further, to envisage the selectivity of this HDA reaction, we have utilized the local nucleophilicity $\mathrm{N}_{\mathrm{k}}$ and electophilicity $\omega_{\mathrm{k}}$ indeces,${ }^{41}$ in which the first new $\sigma$ bond will take place by the most favorable interaction between two more nucleophilic and electrophilic sites and by the Houk rule, ${ }^{41}$ The results are shown in Figure 1.

The selectivity of this reaction is fundamental to determine the most favorable product. So, in Figure 1, we have noted that the most appreciable interactions are between $\mathrm{N} 2$ and $\mathrm{C} 3$ atoms, which belong to the isotellurazole $\mathbf{1}$ and the acetylenic dienophile $\mathbf{2}$, respectively. The local nucleophilic index of $\mathrm{N} 2$ is $4.83 \mathrm{eV}$ that represents the major nucleophilic value of isotellurazole; furthermore, the local electrophilic index of $\mathrm{C} 3$ is $17.68 \mathrm{eV}$, being classified as the maximum value in the acetylenic dienophile moiety. Therefore, the most favorable interactions would take place between N2 and C3 centers. Subsequently, the ortho/endo adduct is the most stable product. Similarly, Houk rule reveals that the highest values of the coefficients of molecular orbital HOMO/LUMO is appreciated between N2 and $\mathrm{C} 3$ atoms and is followed by $\mathrm{C} 1$ and $\mathrm{C} 4$ interactions. Subsequently, it provides the ortho/endo adduct as majority product.

\subsection{Analysis of the stationary points involved in the two regioisomeric patterns associated with the endo approach of isotellurazole $\mathbf{1}$ with acetylenic dienophile 2}

In order to evaluate the most stable regioisomeric channel in this HDA reaction, the most relevant features of

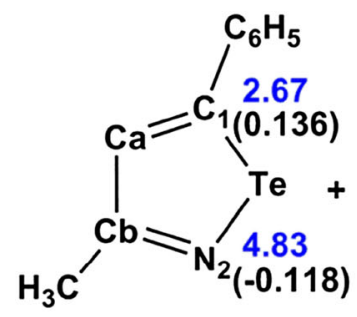

1

Isotellurazole

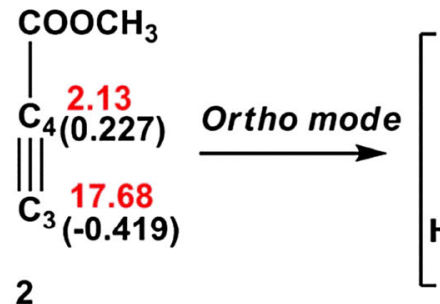

2

Acetylenic dienophile

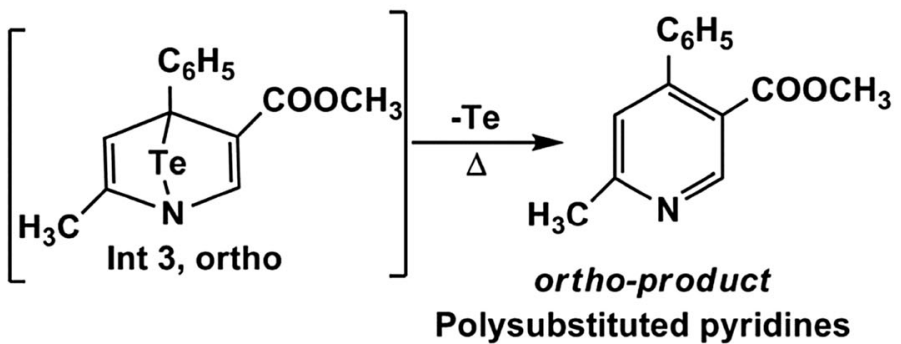

Polysubstituted pyridines

Figure 1. Schematic regioselectivity by using the local nucleophilicity $\mathrm{N}_{\mathrm{k}}\left(\mathbf{1}\right.$, in blue) and electophilicity $\omega_{\mathrm{k}}(\mathbf{2}$, in red) indices (eV) and Houk rule (in parentheses). 

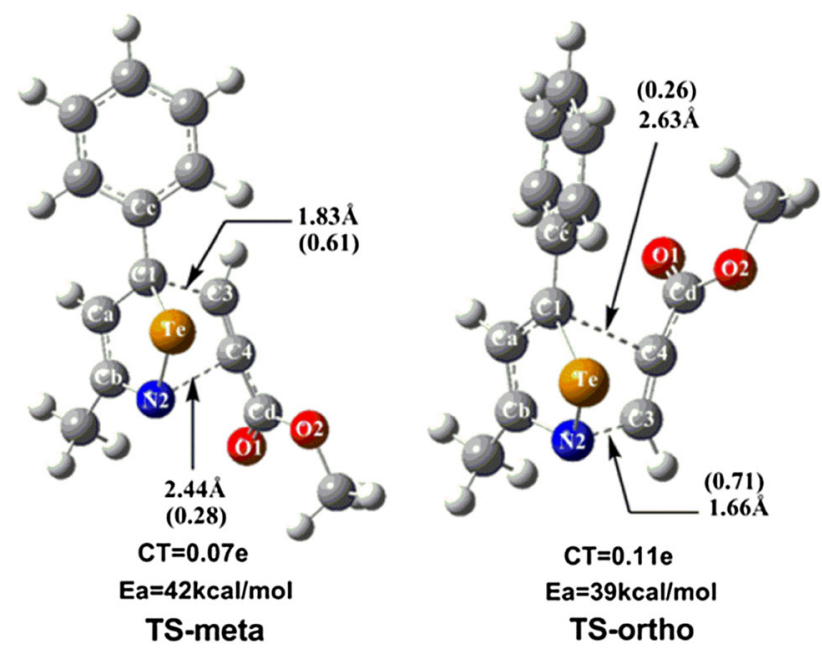

Figure 2. Bond distances $(\AA)$ ), and Wiberg index (given in parentheses) of ortho and meta transition state structures.

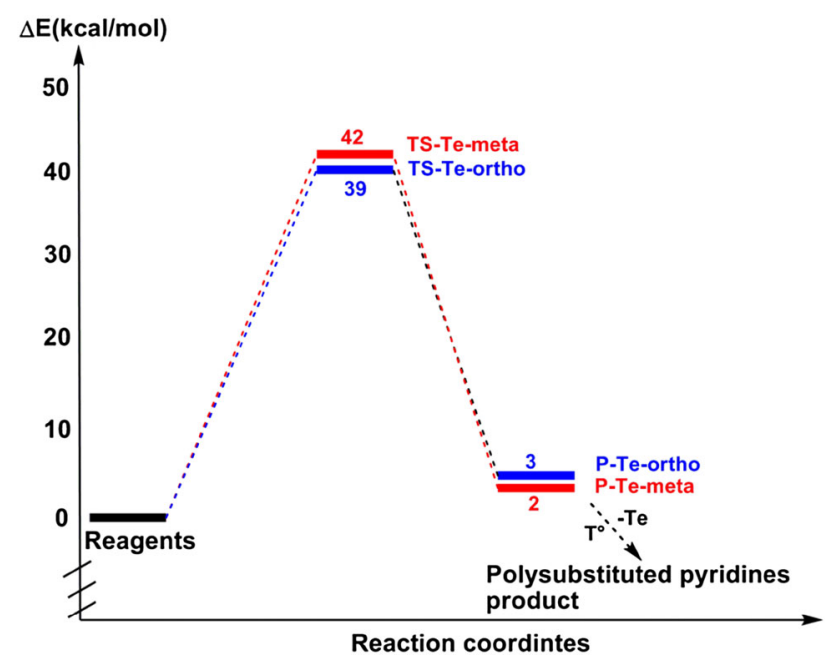

Figure 3. Energy profile in the gas phase for the HDA reaction between isotellurazole $\mathbf{1}$ and acetylenic dienophile $\mathbf{2}$.

the endo regioisomer of $\mathrm{TS}_{\text {ortho }}$ and $\mathrm{TS}_{\text {meta }}$ are given in Figures 2 and 3. However, in this study we have utilized the most suitable B3LYP/Lanl2dz basis set level to the heavy atom and the first- and second-row atoms are represented by the $6-31+\mathrm{g}(\mathrm{d})$ basis set, for rapidity and reliability of the results. An analysis of the potential energy surface (PES) is performed in the gas phase at $298 \mathrm{~K}$, the results show that this cycloaddition reaction takes place via an asynchronous transition state of both regioisomeric channels, in which Wiberg index allows us to note that the bond distances are completely different. The new bonds of N2-C3 and C1-C3 involved of the ortho and meta regioisomeric patterns have the smallest distances, in which the bond distances are $1.66 \AA(0.71)$ and $1.83 \AA$ (0.61) (Figure 2). Subsequently, this HDA reaction is highly asynchronous. As a consequence, N2-C3 and C1-C3 bonds will be formed first along IRC of both ortho and meta adducts, respectively. On the other hand, the thermodynamic results show that the mechanism of meta regioisomeric process is highly energetic, such as that we have established that the activation energies are $39.4 \mathrm{kcal} / \mathrm{mol}$ and 42.1 $\mathrm{kcal} / \mathrm{mol}$ for ortho and meta, respectively; likewise, the calculation of the free energies of activation $\Delta \mathrm{G}$ provides a similar outcome, the barrier activation of ortho adduct is somewhat smaller compared with meta regioisomeric process. We have found that, $44.2 \mathrm{kcal} / \mathrm{mol}$ for ortho and $46.5 \mathrm{kcal} / \mathrm{mol}$ for meta structure. Consequently, the most favorable adduct of this reaction is ortho regioisomer, and therefore the activation barriers of both channel is very high. This is in good agreement with the feeble charge transfer; NBO analysis reveals that the charge transfer is about $0.11 \mathrm{e}$ and $0.07 \mathrm{e}$ of ortho and meta regioisomer, respectively. Unfortunately, comparable thermodynamic results related to the $\mathrm{O}, \mathrm{N}$ or $\mathrm{S}$ bridged atoms of azadiene moiety are unavailable in the literature. It is interesting to note that these intermediary cycloadducts are not having sufficient stability to compare with the reagent $(3.4 \mathrm{kcal} / \mathrm{mol}$ for Te-ortho intermediate and $2.1 \mathrm{kcal} / \mathrm{mol}$ for Te-meta intermediate). Subsequently, these products would probably lose the Te atom easily in thermal conditions to give polysubstituted pyridines as final product.

\subsection{ELF bonding analysis of the bond-formation/breaking step in the IRC path in the HDA reaction of isotellurazole $\mathbf{1}$ with acetylenic dienophile 2}

In this section, we focus to understand the molecular mechanism, and also to comprehend the asynchronous bond-formation in this HDA reaction; likewise, an estimation of the Te-bridged contribution to the reactivity is fundamental. Our aim is to characterize the distribution of electronic density along the progress of the reaction. For this purpose, an ELF analysis along IRC of the most favorable endo/ortho channel was performed. The electronic populations of the most relevant ELF valence basins of selected structures along IRC are listed in Table 2, while the attractor positions for the most relevant points associated with the formation of the $\mathrm{C} 1-\mathrm{C} 4$ and N2-C3 single bonds, are shown in Figure 4.

For a greater understanding of bond formation in this reaction, the electronic population obtained from ELF analysis for some attractor showed that C3-C4 triple bonds of dienophile (2) presents three disynaptic basins $\mathrm{V}(\mathrm{C} 3, \mathrm{C} 4), \mathrm{V}^{\prime}(\mathrm{C} 3, \mathrm{C} 4)$ and $\mathrm{V}(\mathrm{C} 3, \mathrm{C} 4)$, whose electronic population is $2.48 \mathrm{e}, 2.39 \mathrm{e}$ and $0.23 \mathrm{e}$, respectively. Whereas, in phase I this $\mathrm{C} 3-\mathrm{C} 4$ triple bonds would change sequentially to double bonds $(2 \pi \rightarrow \pi)$. 
Table 2. Valence basin populations of the most relevant points calculated from the ELF of HDA reaction of isotellurazole with acetylenic dienophile, associated with the $\mathrm{C} 1-\mathrm{C} 4$ and N2-C3 bond-formation step. Bond order (Wiberg index) and charge transfer in $e$ (NBO).

\begin{tabular}{|c|c|c|c|c|c|c|c|c|c|c|c|c|}
\hline Phase & $\mathrm{R}$ & I & II & III & IV & $\mathrm{V}$ & VI & VII (TS) & VIII & IX & $X$ & PR \\
\hline $\mathrm{d}(\mathrm{C} 1-\mathrm{C} 4)$ & 5.30 & 3.00 & 2.88 & 2.80 & 2.74 & 2.68 & 2.65 & 2.63 & 2.45 & 2.22 & 2.05 & 1.56 \\
\hline d(N2-C3) & 6.65 & 2.24 & 2.16 & 1.91 & 1.80 & 1.74 & 1.70 & 1.66 & 1.60 & 1.57 & 1.55 & 1.47 \\
\hline $\mathrm{BO}(\mathrm{C} 1, \mathrm{C} 4)$ & 0.001 & 0.034 & 0.051 & 0.104 & 0.147 & 0.198 & 0.227 & 0.257 & 0.355 & 0.549 & 0.633 & 0.992 \\
\hline $\mathrm{BO}(\mathrm{N} 2, \mathrm{C} 3)$ & 0.020 & 0.131 & 0.184 & 0.373 & 0.496 & 0.617 & 0.668 & 0.712 & 0.803 & 0.886 & 0.911 & 1.013 \\
\hline CT & 0.007 & 0.040 & 0.099 & 0.128 & 0.133 & 0.121 & 0.113 & 0.107 & 0.059 & 0.027 & 0.060 & 0.129 \\
\hline $\mathrm{V}(\mathrm{C} 1)$ & & & & & & & & & & 0.33 & 0.46 & \\
\hline$V^{\prime}(\mathrm{C} 1)$ & & & & & & & & & & & & 0.72 \\
\hline V(N2) & & & & & & 0.30 & & & & & & \\
\hline $\mathrm{V}^{\prime}(\mathrm{N} 2)$ & 3.33 & 3.14 & 3.17 & 3.10 & 3.12 & 2.87 & 2.81 & 2.78 & 2.73 & 2.73 & 2.74 & 2.81 \\
\hline V(C3) & & & & & 0.14 & 0.26 & & & & & & \\
\hline $\mathrm{V}(\mathrm{C} 4)$ & & & & & & & 0.60 & 0.68 & 0.75 & 0.87 & 0.89 & \\
\hline $\mathrm{V}(\mathrm{C} 1, \mathrm{Ca})$ & 3.24 & 3.06 & 2.96 & 2.84 & 2.75 & 2.68 & 2.63 & 2.60 & 2.45 & 2.25 & 2.19 & 2.05 \\
\hline $\mathrm{V}^{\prime}(\mathrm{C} 1, \mathrm{Ca})$ & 3.24 & 3.06 & & & & & & & & & & \\
\hline $\mathrm{V}(\mathrm{Ca}, \mathrm{Cb})$ & 2.51 & 2.59 & 2.73 & 2.92 & 3.04 & 3.13 & 3.20 & 3.23 & 3.37 & 3.53 & 3.59 & 1.89 \\
\hline$V^{\prime}(\mathrm{Ca}, \mathrm{Cb})$ & & & & & 3.04 & 3.13 & 3.19 & 3.23 & 3.37 & 3.53 & 3.59 & 1.83 \\
\hline $\mathrm{V}(\mathrm{Cb}, \mathrm{N} 2)$ & 2.57 & 2.47 & 2.33 & 2.11 & 1.96 & 1.84 & 1.80 & 1.76 & 1.67 & 1.59 & 1.58 & 1.55 \\
\hline $\mathrm{V}^{\prime}(\mathrm{Cb}, \mathrm{N} 2)$ & 2.57 & & & & & & & & & & & \\
\hline $\mathrm{V}(\mathrm{N} 2, \mathrm{Te})$ & 1.19 & 1.27 & 1.32 & 1.48 & 1.52 & 1.53 & 1.53 & 1.52 & 1.48 & 1.42 & 1.38 & 1.08 \\
\hline $\mathrm{V}(\mathrm{C} 1, \mathrm{Te})$ & 1.82 & 1.83 & 1.85 & 1.88 & 1.89 & 1.91 & 1.92 & 1.92 & 1.97 & 1.74 & 1.66 & \\
\hline $\mathrm{V}(\mathrm{C} 1, \mathrm{Cc})$ & 2.16 & 2.24 & 2.25 & 2.26 & 2.28 & 2.29 & 2.30 & 2.30 & 2.29 & 2.24 & 2.20 & 2.18 \\
\hline $\mathrm{V}(\mathrm{C} 4, \mathrm{Cd})$ & 2.63 & 2.84 & 2.89 & 3.13 & 3.27 & 3.43 & 2.89 & 2.87 & 2.82 & 2.68 & 2.62 & 2.55 \\
\hline $\mathrm{V}(\mathrm{C} 1, \mathrm{C} 4)$ & & & & & & & & & & & & 2.03 \\
\hline $\mathrm{V}(\mathrm{N} 2, \mathrm{C} 3)$ & & & & & & & 0.71 & 0.81 & 1.01 & 1.21 & 1.25 & 1.58 \\
\hline $\mathrm{V}(\mathrm{C} 3, \mathrm{C} 4)$ & 2.48 & 2.47 & 2.46 & 2.37 & 2.26 & 2.17 & 2.12 & 2.08 & 2.00 & 1.95 & 1.94 & 1.80 \\
\hline $\mathrm{V}^{\prime}(\mathrm{C} 3, \mathrm{C} 4)$ & 2.39 & 2.42 & 2.40 & 2.28 & 2.21 & 2.13 & 2.10 & 2.08 & 2.00 & 1.94 & 1.93 & 1.73 \\
\hline V”(C3,C4) & 0.23 & & & & & & & & & & & \\
\hline $\mathrm{V}(\mathrm{Te})$ & 2.33 & 2.33 & 2.34 & 2.35 & 2.37 & 2.38 & 2.39 & 2.40 & 2.42 & 2.44 & 2.45 & 2.54 \\
\hline$V^{\prime}(\mathrm{Te})$ & 2.39 & 2.41 & 2.42 & 2.42 & 2.42 & 2.42 & 2.42 & 2.42 & 2.42 & 2.44 & 2.44 & 2.52 \\
\hline V"'(Te) & & & & & & & & & & & & 0.33 \\
\hline
\end{tabular}

Equally, in phase I and II, C1-Ca and Cb-N2 double bonds of azadiene (1) which has two pairs of disynaptic basins $\mathrm{V}(\mathrm{C} 1, \mathrm{Ca}) ; \mathrm{V}^{\prime}(\mathrm{C} 1, \mathrm{Ca})$ and $\mathrm{V}(\mathrm{Cb}, \mathrm{N} 2) ; \mathrm{V}^{\prime}(\mathrm{Cb}, \mathrm{N} 2)$, having electron density of $3.24 \mathrm{e}$ and $2.57 \mathrm{e}$, would transform finally to the single bond $(\pi \rightarrow \sigma)$. For this instance, at the beginning of the reaction, the monosynaptic basins of $\mathrm{V}(\mathrm{C} 3, \mathrm{C} 4), \mathrm{V}^{\prime}(\mathrm{C} 3, \mathrm{C} 4), \mathrm{V}(\mathrm{C} 1, \mathrm{Ca})$ and $\mathrm{V}(\mathrm{Cb}, \mathrm{N} 2)$ would sequentially lose more electron density until the end of the reaction. In this sense, in phase IV, Ca-Cb single bond of azadiene (1) with electronic population $2.51 \mathrm{e}$ becomes double bond $(\sigma \rightarrow \pi)$, which presents two disynaptic basins of $\mathrm{V}(\mathrm{Ca}, \mathrm{Cb})$ and $\mathrm{V}^{\prime}(\mathrm{Ca}, \mathrm{Cb})$ integrating $3.04 \mathrm{e}$ of each one; however these latter basins benefit to an important electron density along IRC. The most relevant change is located in phases $\mathrm{IV}$ and $\mathrm{V}$, as revealed in our analysis that the appearance of two monosynaptic basins $\mathrm{V}(\mathrm{C} 3)$ and $\mathrm{V}(\mathrm{N} 2)$ associated with the $\mathrm{C} 3$ and $\mathrm{N} 2$ atoms, which integrate to $0.14 \mathrm{e}$ and $0.30 \mathrm{e}$, respectively. So, in this case, the two pseudo-radicals, monosynaptic basins are necessary for the formation of the new bond C3-N2 and completed, whereas the other terminal monosynaptic basin at the $\mathrm{C} 1$ and $\mathrm{C} 4$ atoms are not yet formed. Exactly, in phase VI, a new bond of C3-N2 is created with an electronic population of $0.71 \mathrm{e}$, similarly at this phase, a new monosynaptic basin under $\mathrm{C} 4$ atom has appeared and integrates to $0.60 \mathrm{e}$. In phase IX, another relevant change takes place at the azadiene moiety (1) such as a new monosynaptic basin of $\mathrm{V}(\mathrm{C} 1)$ appeared finally, and integrates to $0.33 \mathrm{e}$. Therefore, the formation of the attractor responsible for the formation of the $\mathrm{C} 1-\mathrm{C} 4$ bond is now completed, in this way, the two monosynaptic basins related to the $\mathrm{C} 1$ and $\mathrm{C} 4$ atoms merge into one disynaptic basin of $\mathrm{V}(\mathrm{C} 1, \mathrm{C} 4)$ associated with the $\mathrm{C} 1-\mathrm{C} 4 \sigma$ bond at the end of the reaction, whose electronic population is $2.03 \mathrm{e}$.

Interestingly, this mechanistic process takes place through two-stage one-step; the first stage between phase I and phase VI, while the second stage between phase VII and the product. Simultaneously, the charge transfer (CT) has known two important stages, the first at the formation of $\mathrm{C} 3-\mathrm{N} 2$ bond and the second, at 
<smiles>OOB1OOOOOOOOOOOO1</smiles>
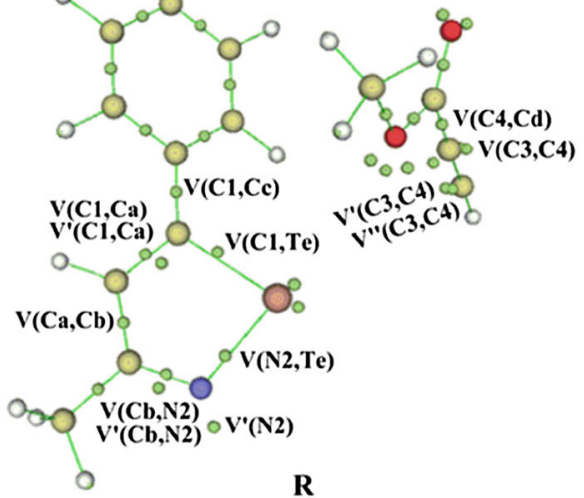

$\mathbf{R}$
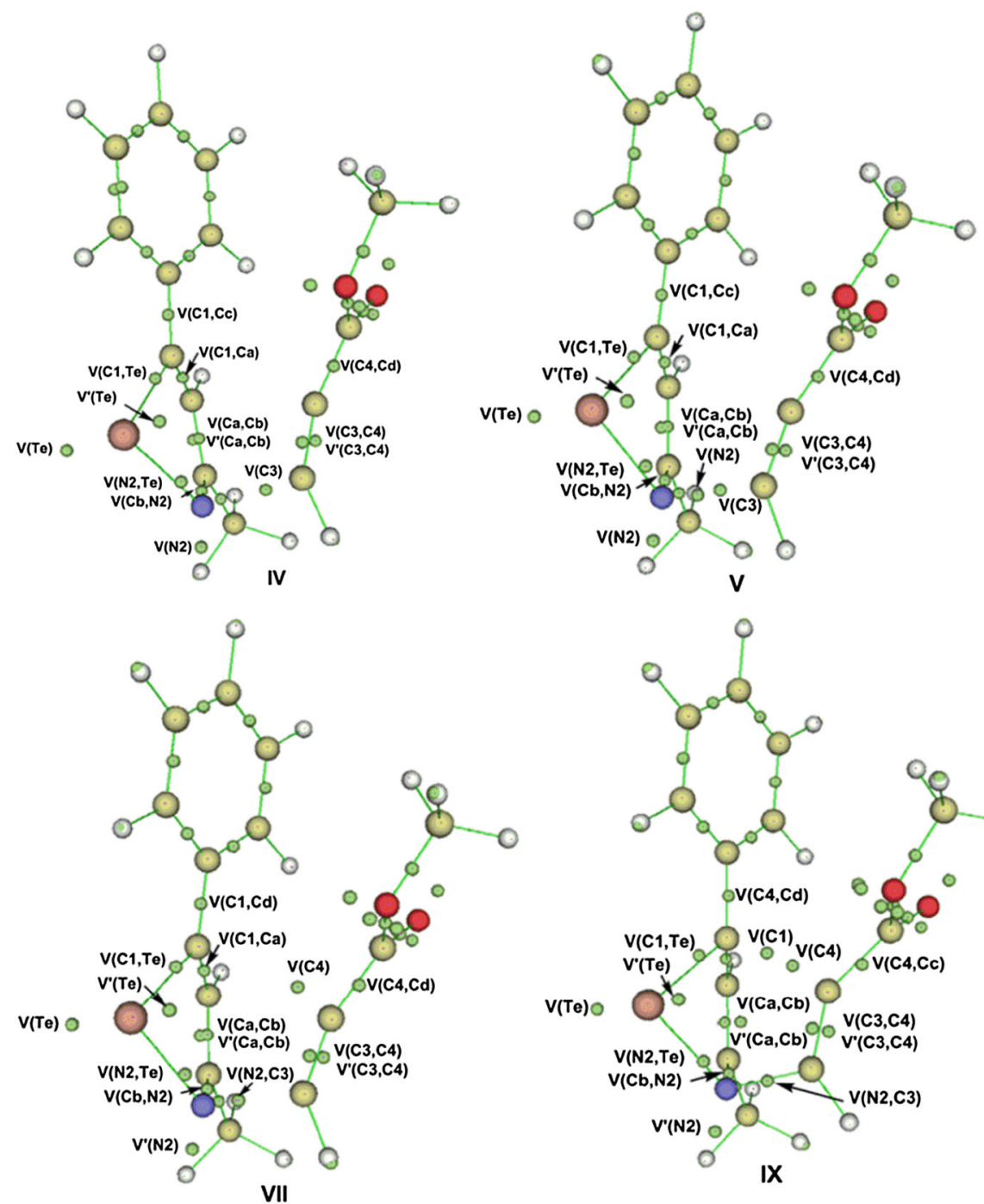
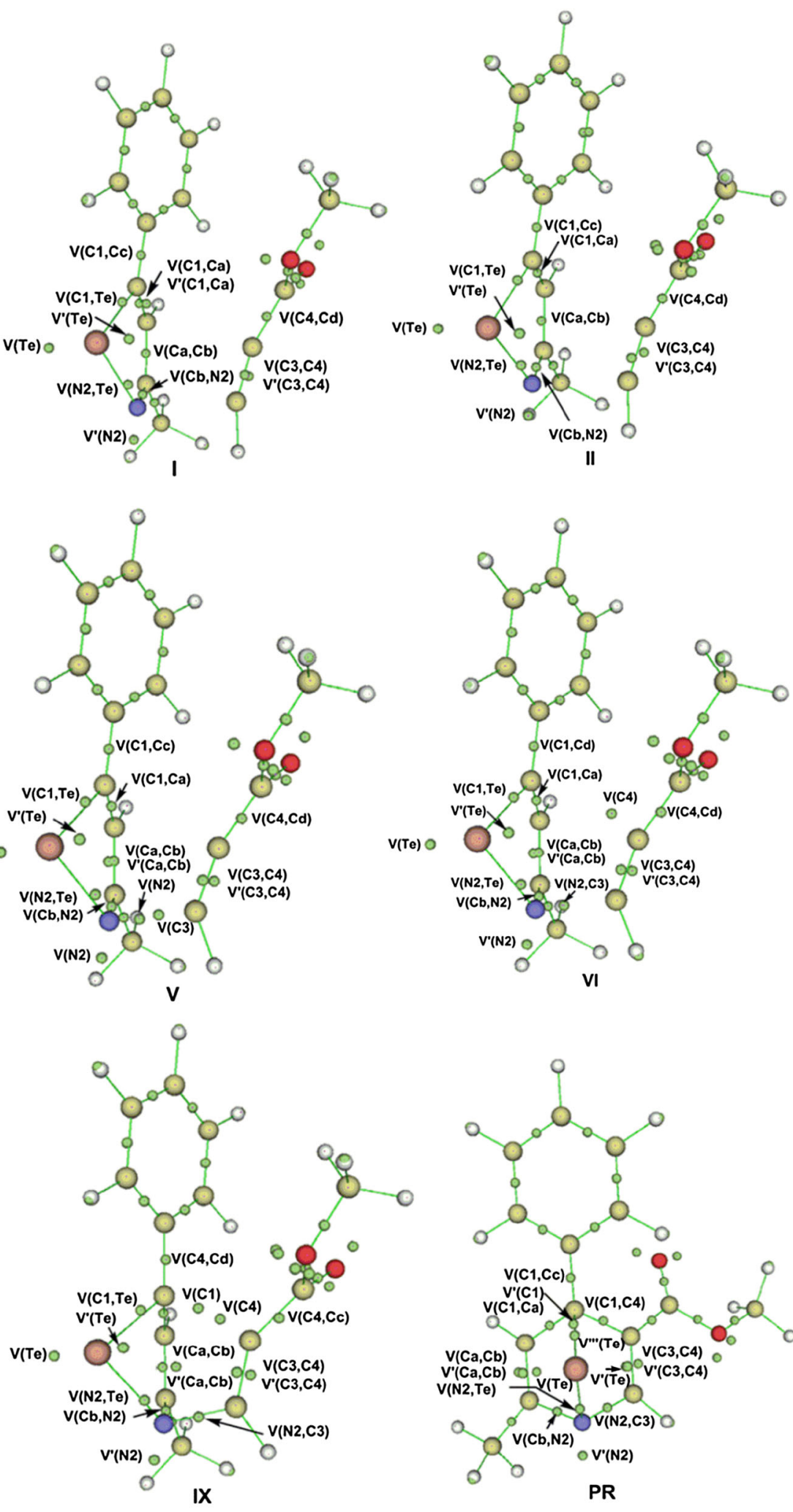

Figure 4. ELF attractors of some selected points of the IRC associated with the formation of the new C-C and N-C single bond in the HDA reaction of isotellurazole 1 with acetylenic dienophile 2.

the formation of the $\mathrm{C} 1-\mathrm{C} 4$ bond, although maximum $\mathrm{CT}$ along IRC occurs in phase IV corresponding with the formation of the first bond, 0.133e. Otherwise, the electron density of the disynaptic basin $\mathrm{V}(\mathrm{C} 1, \mathrm{Te})$ and $\mathrm{V}(\mathrm{N} 2, \mathrm{Te})$ associated with the $\mathrm{C} 1-\mathrm{Te}$ and $\mathrm{N} 2-\mathrm{Te}$ bonds proceed step by step to decrease more, until the split 


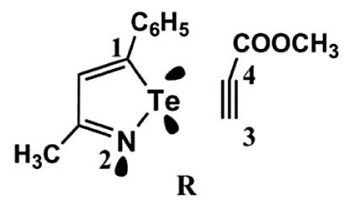<smiles>CC(=O)C=C[C@]1(I)[C@H](C)C=C(C)N1C</smiles><smiles>CCC1=CC(C)=[N+](C)C1(C)C</smiles>

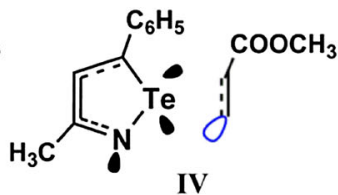

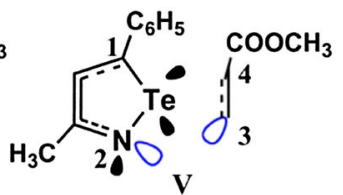

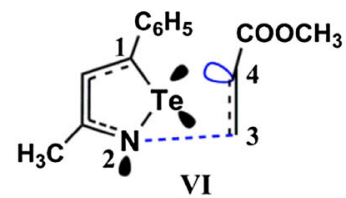

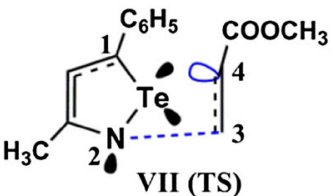

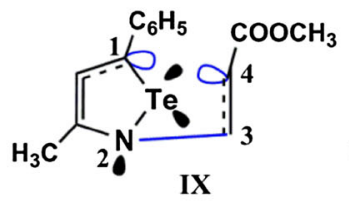

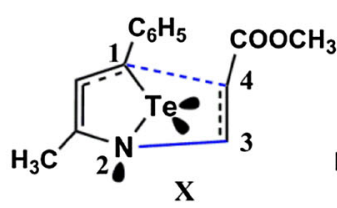

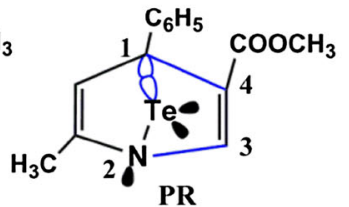

Figure 5. The bonding changes at selected points involved in the HDA reaction of isotellurazole 1 with acetylenic dienophile 2.

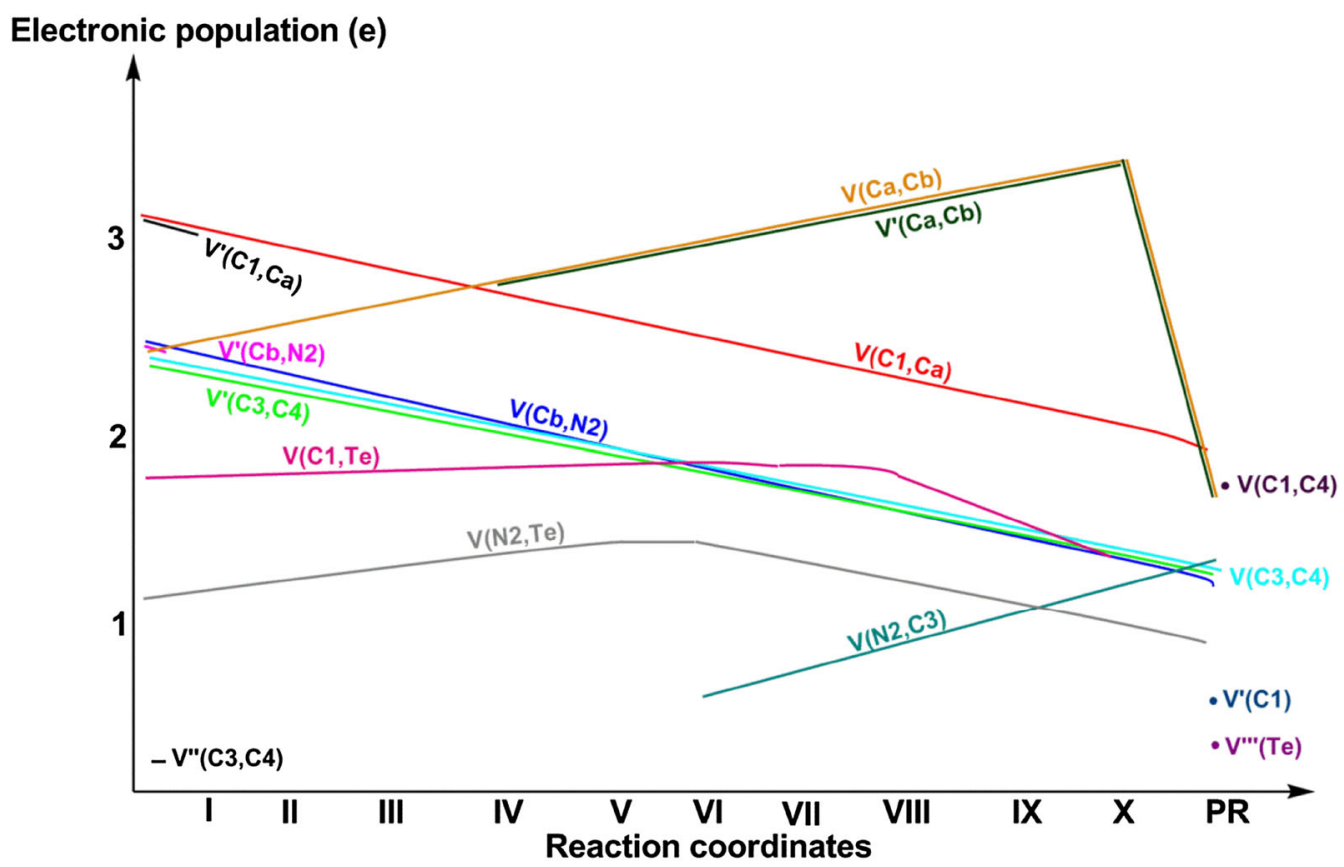

Figure 6. Electronic population, (ine), of some relevant attractors along IRC.

of these basins at the end of the reaction, $\mathrm{V}(\mathrm{C} 1)$ and $\mathrm{V}(\mathrm{Te})$. This major change has facilitated the excision of the Te atom from the intermediary cycloadduct to yield pyridine molecule in accordance with the experimentally observed results. ${ }^{6}$ Moreover, the formation of the new C-C and N-C $\sigma$ bond appeared highly asynchronous, in which Wiberg index calculation reveals that the formation of N2-C3 $\sigma$ bond is always in advance to that of $\mathrm{C} 1-\mathrm{C} 4 \sigma$ bond, as shown in Table 2; whereas, note that Wiberg index (N2-C3) $>$ Wiberg index $(\mathrm{C} 1-$ $\mathrm{C} 4)$. A conclusion has been attained from this study, that the HDA reaction proceeds through two-stages one-step via pseudo-radical formation at the most relevant center between azadiene moiety of $\mathbf{1}$ and the acetylenic part of the dienophile $\mathbf{2}$, so the first stage is located between the reagent and phase VI, in which N2-C3 $\sigma$ single bond will be formed first, while in the second stage between the phase VII and the product, where $\mathrm{C} 1-\mathrm{C} 4 \sigma$ single bond is formed completely at the end of the reaction. So, this mechanism is a not concerted process. A summarized picture illustrating the bonding changes along selected points involved in this HDA reaction is presented in Figure 5 , while a representation of the change of electron density along some relevant attractors is given in Figure 6.

Some conclusions can be drawn from this study. The large electronic population under lone pairs of Te atom, as well as the moderate electronic population of the N2Te and C1-Te bonds, and the split of the C1-Te bond in the end of the reaction reveal that N2-Te and C1Te bonds are totally polarized and that the total electron density is concentrated either in $\mathrm{N} 2$ or Te as well as in C1 
Table 3. Atomic contribution to electronic population (in e) of N2-Te and C1-Te bonds.

\begin{tabular}{|c|c|c|c|c|c|c|c|c|}
\hline \multirow[t]{3}{*}{ Phases } & \multicolumn{4}{|c|}{ N2-Te Bond } & \multicolumn{4}{|c|}{ C1-Te Bond } \\
\hline & \multicolumn{2}{|l|}{$\mathrm{N} 2$} & \multicolumn{2}{|l|}{$\mathrm{Te}$} & \multicolumn{2}{|l|}{$\mathrm{C} 1$} & \multicolumn{2}{|l|}{$\mathrm{Te}$} \\
\hline & Population & $\%$ & Population & $\%$ & Population & $\%$ & Population & $\%$ \\
\hline $\mathrm{R}$ & 1.15 & 100 & 0.00 & 0 & 1.82 & 100 & 0.00 & 0 \\
\hline $\mathrm{I}$ & 1.33 & 103 & 0.00 & 0 & 1.84 & 101 & 0.00 & 0 \\
\hline II & 1.40 & 106 & 0.00 & 0 & 1.86 & 100 & 0.00 & 0 \\
\hline III & 1.47 & 100 & 0.00 & 0 & 1.87 & 100 & 0.00 & 0 \\
\hline IV & 1.52 & 100 & 0.00 & 0 & 1.89 & 100 & 0.00 & 0 \\
\hline V & 1.53 & 100 & 0.00 & 0 & 1.91 & 100 & 0.00 & 0 \\
\hline VI & 1.51 & 98.7 & 0.00 & 0 & 1.92 & 100 & 0.00 & 0 \\
\hline VII & 1.51 & 100 & 0.00 & 0 & 1.94 & 101 & 0.00 & 0 \\
\hline VIII & 1.48 & 100 & 0.00 & 0 & 1.97 & 100 & 0.00 & 0 \\
\hline IX & 1.44 & 105 & 0.00 & 0 & 2.04 & 117 & 0.00 & 0 \\
\hline $\mathrm{X}$ & 1.43 & 103 & 0.00 & 0 & 1.74 & 105 & 0.00 & 0 \\
\hline
\end{tabular}
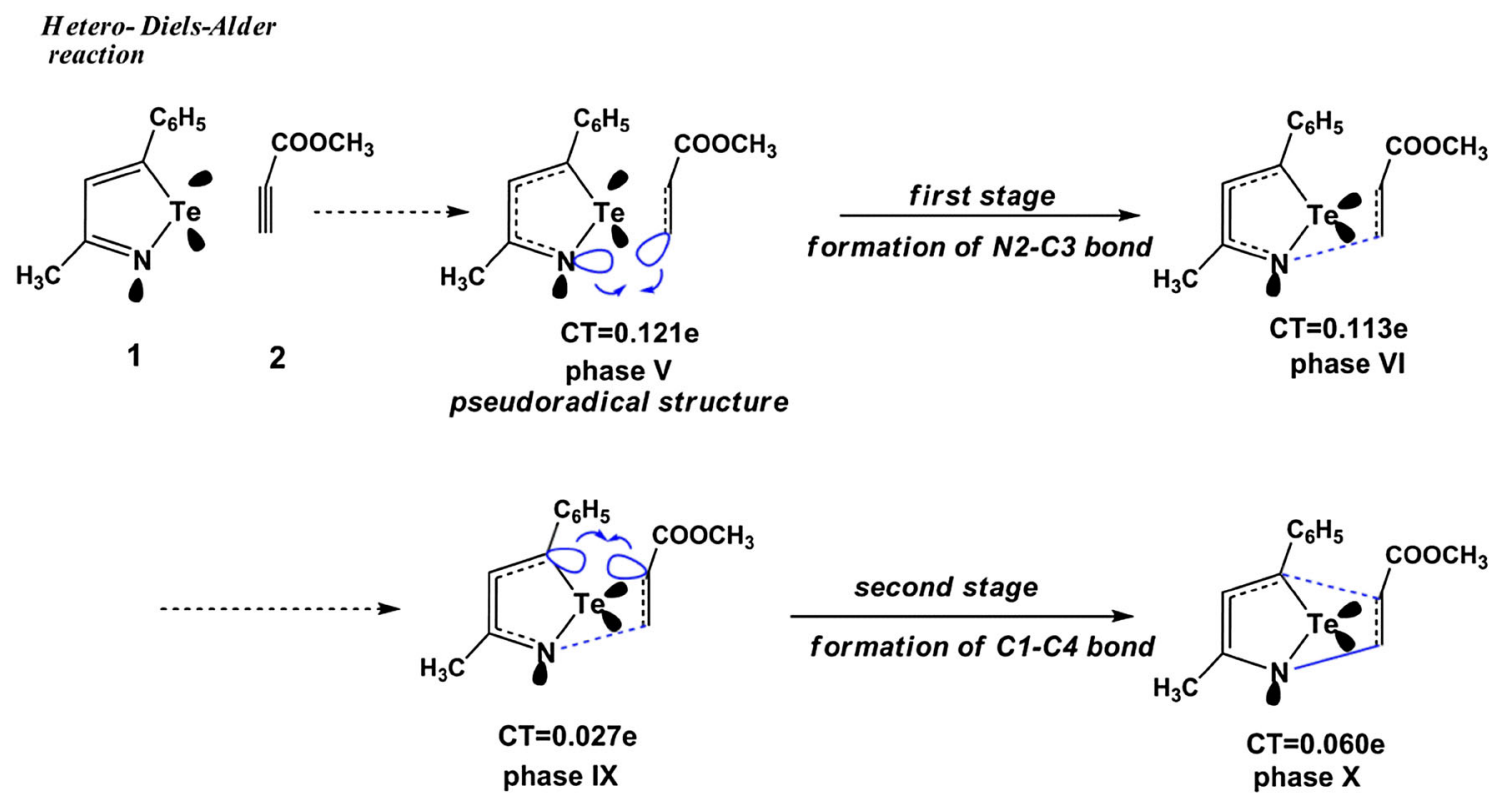

Figure 7. $\mathrm{C}-\mathrm{C}$ bond formation model in the Hetero-Diels-Alder reaction of isotellurazole 1 with acetylenic dienophile 2.

or Te. To this end, we calculate the atomic contribution to the electronic population of the $\mathrm{N} 2-\mathrm{Te}$ and $\mathrm{C} 1-\mathrm{Te}$ bonds, and the results are given in Table 3 .

Due to the low hetero-aromaticity of Te atom, the total electronic population of both $\mathrm{C} 1-\mathrm{Te}$ and $\mathrm{N} 2-\mathrm{Te}$ bonds have been absorbed by the $\mathrm{C} 1$ and $\mathrm{N} 2$ atoms (Table 3), these latter atoms represent the most nucleophilic centers of azadiene (1) reagent. An inequitable reorganization of electron density makes these bonds extremely polarized, and thus the electronic population of the tellurium atom is concentrated under lone pairs, and it makes this atom electronically very rich. So, on the one hand, the feeble electronegativity character of the heavy chalcogen-bridged atom has helped for the whole concentration of electron density at the $\mathrm{N} 2$ and $\mathrm{C} 1$ atoms, and subsequently polarizes $\mathrm{C} 1-\mathrm{Te}$ and $\mathrm{N} 2-$ Te bonds. These factors explain the facile breaking of these bonds and the subsequent removal of the tellurium atom at the end of the reaction. On the other hand, the pseudo inactive character of Te atom (neither electron donor nor attractor) has negatively influenced the development of this reaction (high activation energy). Simultaneously, Te atom plays a small role in the high regio-selectivity observed in this Hetero-Diels-Alder reaction, due to the trivial charge transfer of the $\mathrm{C} 1$ Te-N2 bridged sequence. 


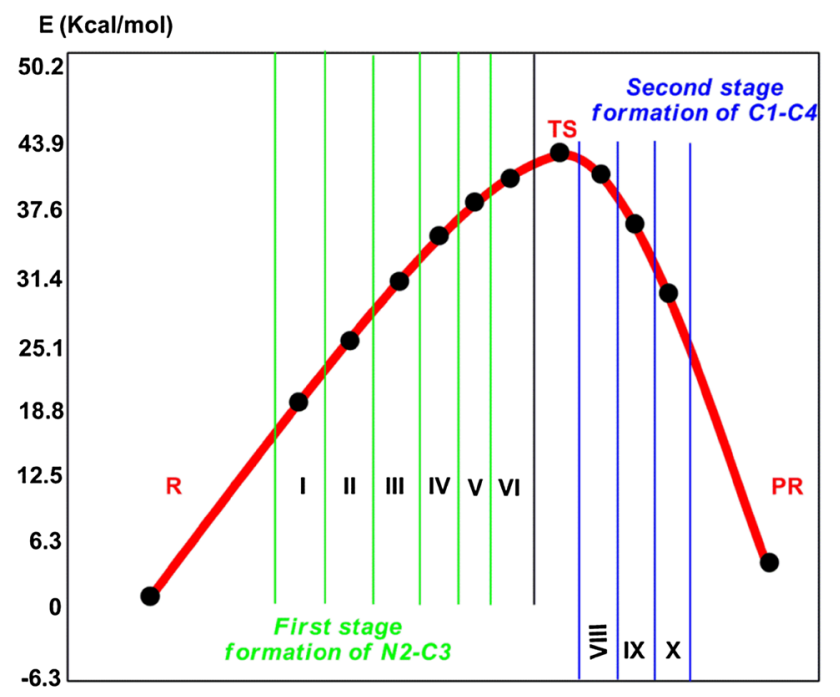

Reaction coordinates

Figure 8. Energy profile, in ( $\mathrm{kcal} / \mathrm{mol})$, along two-stage one-step mechanism associated with the formation of the $\mathrm{C} 1-\mathrm{C} 4$ and N2-C3 single bonds of the HDA reaction of isotellurazole $\mathbf{1}$ with acetylenic dienophile $\mathbf{2}$.

Consequently, the formation of the pseudo-radical at $\mathrm{N} 2$ and $\mathrm{C} 3$ atoms is due mainly to the asymmetric distribution of electron-density in the isotellurazole and acetylenic dienophile moieties. Therefore, the asymmetric formation of these pseudo-radical centers of two reagents is responsible for the asynchronous bond formation and the regioselectivity observed in this HDA reaction. Accordingly, this HDA reaction takes place along two-stage one-step mechanism (Figure 7). Whereas, in Figure 8, we have presented the relative position of the selected points along IRC with respect to the energy profile along two-stage one-step mechanism of the HDA reaction between isotellurazole $\mathbf{1}$ and acetylenic dienophile $\mathbf{2}$.

\section{Conclusions}

The molecular mechanism of the Hetero-Diels-Alder (HDA) reaction of isotellurazole with acetylenic dienophile has been studied at the B3LYP/lanl2dz + $6-31+G(d)$ level of theory. A conceptual DFT and a thermodynamic study reveal that the ortho/endo mode is the most stable and favorable adduct in this reaction. Importantly, this reaction takes place along two-stage one-step mechanism. In the first stage of the reaction, the N2-C3 bond is formed between the pseudo-radical centers positioned at the most electrophilic carbon (C3) of acetylenic dienophile $\mathbf{2}$, and the most nucleophilic center based on electron density provided by the lone pairs of the N2 nitrogen of isotellurazole 1. In the second stage of the reaction, the $\mathrm{C} 1-\mathrm{C} 4$ bond is formed between the pseudo-radical center positioned at the $\mathrm{C} 1$ carbon of izotellurazole and the $\mathrm{C} 4$ carbon of acetylenic dienophile. Furthermore, the low hetero-aromaticity of the Te atom makes C1-Te and N2-Te bonds extremely polarized, and thus, the weak electronegativity character of this heavy chalcogen-bridged atom has helped in the transfer of electron density to the $\mathrm{N} 2$ and $\mathrm{C} 1$ atoms, assisting the easy removal of tellurium atom from the intermediary adduct in thermal conditions. Simultaneously, the pseudo-neutral character of the Te atom has increased the activation energy and this cycloaddition [4+2] pathway is highly energetic. Thus, the electron density characterization along IRC reaction path is useful to explain the molecular mechanism and the experimentally observed results.

\section{Supplementary Information (SI)}

Coordinates, energies and frequencies for all the stationary points as well as the IRC of the most favorable regio-isomeric channel involved in HDA reaction are available in Supplementary Information which is available at www.ias.ac.in/ chemsci.

\section{References}

1. Hutton J, Potts B and Southern D F 1979 Synthesis of 3,4-bis-Acetoxymethyl-Furan Synth. Commun. 9789

2. Boger D L 1983 Diels-alder reactions of azadienes Tetrahedron 392869

3. Wilkie G D, Elliott G I, Blagg B S J, Wolkenberg S E, Soenen D R, Miller M M, Pollack S and Boger D L 2002 intramolecular Diels-Alder and tandem intramolecular Diels-Alder/1,3-Dipolar cycloaddition reactions of 1,3,4-Oxadiazoles J. Am. Chem. Soc. 12411292

4. Takikawa Y, Hikage S, Matsuda Y, Higashiyama K, Takeishi Y and Shimada K 1991 Novel conversion of selenium-containing five-membered aromatics to nitrogen-containing six-membered aromatics via Hetero Diels-Alder reaction with acetylenic dienophile Chem. Lett. 202043

5. Cava M P and Saris L E 1975 Synthesis of anhydro2,3,5-triphenyl-4-hydroxyselenazolium hydroxide, a mesoionic selenium heterocycle J. Chem. Soc. Chem. Commun. 22617

6. Shimada K, Takata Y, Osaki Y, Akiko M, Hisashi K, Maiko S, Shigenobu A, Yuji T and Satoshi O 2009 Regioselective synthesis of polysubstituted pyridines via hetero-Diels-Alder reaction of isotellurazole with acetylenic dienophile Tetrahedron Lett. 506651

7. Soto-Delgado J, Domingo L R and Contreras R 2010 Quantitative characterization of group electrophilicity and nucleophilicity for intramolecular Diels-Alder reactions Org. Biomol. Chem. 83678

8. Paton R S, Steinhardt S E, Vanderwal C D and Houk K N 2011 Unraveling the mechanism of cascade reactions of zincke aldehydes J. Am. Chem. Soc. 1333895 
9. Benallou A, Garmes $\mathrm{H}$ and El Alaoui El Abdallaoui H 2014 Theoretical study of the regioselectivity in the intramolecular Diels-Alder reaction of the molecule triene amide Mor. J. Chem. 2181

10. Benallou A, Garmes H, Knouzi N and El Alaoui El Abdallaoui H 2014 Elucidation of the regioselectivity in hetero diels-alder reaction by utilization of theoretical approaches Phys. Chem. News. 7285

11. Domingo L R and Saez J A 2009 Understanding the mechanism of polar Diels-Alder reactions Org. Biomol. Chem. 73576

12. Berski S, Andres J, Silvi B and Domingo L R 2006 New findings on the Diels-Alder reactions. An analysis based on the bonding evolution theory J. Phys. Chem. A 110 13939

13. Benallou A, El Alaoui El Abdallaoui $\mathrm{H}$ and Garmes $\mathrm{H}$ 2016 Effect of hydrogen bonding on the intramolecular cycloaddition Diels-Alder reaction of triene-amide in an aqueous solution (case of a single molecule of water) Tetrahedron 7276

14. Benallou A, El Alaoui El Abdallaoui H and Garmes H 2016 A conceptual DFT approach towards analysing feasibility of the intramolecular cycloaddition Diels-Alder reaction of triene amide in Lewis acid catalyst J. Chem. Sci. 1281489

15. Krokidis X, Vuilleumier R, Borgis D and Silvi B 1999 A Topological analysis of the proton transfer in $\mathrm{H}_{5} \mathrm{O}_{2}^{+}$Mol. Phys. 96265

16. Krokidis X, Silvi B and Alikhani M E 1998 Topological characterization of the isomerization mechanisms in $\mathrm{XNO}(\mathrm{X}=\mathrm{H}, \mathrm{Cl})$ Chem. Phys. Lett. 29235

17. Diels O and Alder K 1928 Syntheses in hydroaromatic series. I. Addition of diene hydrocarbons Justus. Liebigs. Ann. Chem. 46098

18. Woodward R B and Hoffmann R 1969 The conservation of orbital symmetry Angew. Chem. Int. Ed. Engl. 8781

19. Winkler J D 1996 Tandem Dielsminus signAlder cycloadditions in organic synthesis Chem. Rev. 96 167

20. Carruthers von W 1990 In Cycloaddition reactions in organic synthesis (Pergamon: Oxford)

21. Chen Z and Trudell M L 1996 Chemistry of 7Azabicyclo[2.2.1]hepta-2,5-dienes, 7-Azabicyclo [2.2.1]hept-2-enes, and 7-Azabicyclo[2.2.1]heptanes Chem. Rev. 961179

22. Finguelli F and Tatichi A 2002 In The Diels-Alder reaction. Selected practical methods (New York: Wiley)

23. Gonzalez C and Schlegel H B 1990 Reaction path following in mass-weighted internal coordinates J. Phys. Chem. 945523

24. Fleming I 1976 In Frontier orbitals and organic chemical reactions Ch. 4 (New York: John Wiley)

25. Schlegel H B 1994 In Modern electronic structure theory (Singapore: World Scientific Publishing)

26. Fukui K 1970 Formulation of the reaction coordinate $J$. Phys. Chem. 744161

27. Gonzalez C and Schlegel H B 1991 Improved algorithms for reaction path following: Higher-order implicit algorithms J. Chem. Phys. 955853
28. Reed A E, Curtiss L A and Weinhold F 1988 Intermolecular interactions from a natural bond orbital, donor-acceptor viewpoint Chem. Rev. 88899

29. Tian L and Feiwu C 2012 Multiwfn: A multifunctional wavefunction analyzer J. Comp. Chem. 3580

30. (a) Lee C, Yang W and Parr R G 1988 Development of the Colle-Salvetti correlation-energy formula into a functional of the electron density Phys. Rev. B 37 785; (b) Becke A D 1993 Density-functional thermochemistry. III. The role of exact exchange J. Chem. Phys. 985648

31. Hehre W J, Radom L, Schleyer P v R and Pople J A 1986 In Ab initio molecular orbital theory (New York: Wiley)

32. Frisch M J, Trucks G W, Schlegel H B, Scuseria G E, Robb M A, Cheeseman J R, Scalmani G, Barone V, Mennucci B, Petersson G A, Nakatsuji H, Caricato M, Li X, Hratchian H P, Izmaylov A F, Bloino J, Zheng G, Sonnenberg J L, Hada M, Ehara M, Toyota K, Fukuda R, Hasegawa J, Ishida M, Nakajima T, Honda Y, Kitao O, Nakai H, Vreven T, Montgomery J A, Peralta J E, Ogliaro F, Bearpark M, Heyd J J, Brothers E, Kudin K N, Staroverov V N, Kobayashi R, Normand J, Raghavachari K, Rendell A, Burant J C, Iyengar S S, Tomasi J, Cossi M, Rega N, Millam J M, Klene M, Knox J E, Cross J B, Bakken V, Adamo C, Jaramillo J, Gomperts R, Stratmann R E, Yazyev O, Austin A J, Cammi R, Pomelli C, Ochterski J W, Martin R L, Morokuma K, Zakrzewski V G, Voth G A, Salvador P, Dannenberg J J, Dapprich S, Daniels A D, Farkas O, Foresman J B, Ortiz J V, Cioslowski J and Fox D J 2009 In Gaussian, Revision A.02 (Wallingford CT: Gaussian Inc.)

33. Reed A E and Weinhold F J 1983 Natural bond orbital analysis of near-Hartree-Fock water dimer J. Chem. Phys. 784066

34. Parr R G, Szentpaly L V and Liu S 1999 Electrophilicity Index J. Am. Chem. Soc. 1211922

35. Parr R G and Yang W 1989 In Density functional theory of atoms and molecule (New York: Oxford University Press)

36. Domingo L R, Aurell M J, Perez P and Contreras R 2002 Quantitative characterization of the local electrophilicity of organic molecules. Understanding the regioselectivity on Diels-Alder reactions J. Phys. Chem. A 1066871

37. Domingo L R and Pérez P 2011 The nucleophilicity N index in organic chemistry Org. Biomol. Chem. 97168

38. Kohn W and Sham L 1965 Self-consistent equations including exchange and correlation effects Phys. Rev. 1401133

39. Perez P, Domingo L R, Duque-Norena M and Chamorro E 2009 A condensed-to-atom nucleophilicity index. An application to the director effects on the electrophilic aromatic substitutions J. Mol. Struct. (Theochem) 895 86

40. Contreras R, Fuentealba P, Galván $\mathrm{M}$ and Perez $\mathrm{P}$ 1999 A direct evaluation of regional Fukui functions in molecules Chem. Phys. Lett. 304405

41. Domingo L R, Chamorro E and Perez P 2008 Understanding the reactivity of captodative ethylenes in polar cycloaddition reactions. A theoretical study J. Org. Chem. 734615 